\title{
O USO DO SISTEMA AGROFLORESTAL TAUNGYA NA RESTAURAÇÃO DE RESERVAS LEGAIS: INDICADORES ECONÔMICOS
}

\author{
Elisangela Ronconi Rodrigues*, Laury Cullen Júnior**, Antonio Vicente Moscogliato***, \\ Tiago Pavan Beltrame**** \\ *Bióloga, M.Sc., Doutoranda em Biologia Vegetal, UNESP - elisangelaronconi@terra.com.br \\ **Eng. Florestal, Dr., Instituto de Pesquisas Ecológicas, IPE - 1cullen@stetnet.com.br \\ ***Eng. Florestal, Instituto de Pesquisas Ecológicas, IPE - vicente@ipe.org.br \\ ****Eng. Florestal, M.Sc., Instituto de Pesquisas Ecológicas, IPE - tpavan@ipe.org.br \\ Recebido para publicação: 06/11/2007 - Aceito para publicação: 20/03/2008
}

\begin{abstract}
Resumo
O Pontal do Paranapanema, extremo oeste do estado de São Paulo, é conhecido em todo Brasil devido aos conflitos pela posse de terra, protagonizados pelo MST (Movimento dos Trabalhadores Rurais Sem Terra), que transformaram significantemente a paisagem da região, onde, atualmente, observamse pequenas ilhas de assentamentos rurais imersos numa matriz de grandes pastagens. O Código Florestal prevê que esses assentamentos devam manter, no mínimo, 20\% de área com cobertura vegetal arbórea. Essa área é conhecida como Reserva Florestal Legal e deve ser restaurada caso se encontre degradada. Assim, esta pesquisa se desenvolveu no assentamento Santa Zélia, município de Teodoro Sampaio, São Paulo, numa área de 27,5 hectares de Reserva Legal, onde onze famílias deste assentamento foram responsáveis pela restauração da área, através do sistema Taungya. Três indicadores foram utilizados para a avaliação econômica da área: Valor Presente Líquido (VPL), Relação Benefício-Custo (RB/C) e payback. A partir disso, verificou-se que resultados econômicos apresentaram valores positivos para oito das onze famílias analisadas, levando à conclusão que sistemas agroflorestais podem ser adotados na recuperação de áreas de Reserva Legal em propriedades rurais. Sua maior ou menor viabilidade econômica irá depender de um manejo mais intenso na área para produção agrícola e de preços satisfatórios para venda no mercado.
\end{abstract}

Palavras-chave: Sistema Taungya; reserva legal; indicadores econômicos.

\begin{abstract}
Taungya agroforestry system for restoration of legal reserves: economic indicators. Pontal do Paranapanema, in the extremity west of São Paulo state, is a well known region in Brazil due mainly to the land conflicts, mobilized by the MST (Movement of Landless Rural Workers). This land reform movement has changed the rural landscape, where small forest fragments are today surrounded by human settlements. The São Paulo State Forest Code foresees that these settlements, as well as any rural property, must keep $20 \%$ of its area covered by natural vegetation. This area, socalled Legal Reserve, must be restored if their original vegetation had been removed or impacted. Thus, this research was carried out in Santa Zelia settlement, in Pontal do Paranapanema, located into 27,5 hectares of Legal Reserve area. Eleven families of this settlement were involved in an agroforestry project, through Taungya agroforestry system, where native trees were intercropped with annual crops for restoration this legal reserve. Three variables had been used for the economic evaluation in the area: Liquid Present Value (VPL), Relation Benefit-Cost (RB/C) and payback. The results showed positive values for eight out to the eleven analyzed families, leading to a conclusion that Agroforestry Systems can be adopted in the recovery of areas of Legal Reserve in rural properties. Its economic viability will mainly depend on intensifying the intercropping and on satisfactory market prices for the annual crops.

Keywords: Taungya system; legal reserve; economic variables.
\end{abstract}

\section{INTRODUÇÃO}

O início dos sistemas agrícolas pertence a um passado pouco registrado na história. Estima-se que as primeiras lavouras tenham sido intencionalmente semeadas há cerca de dez mil anos, por 
civilizações que nasceram e cresceram tendo como base a utilização de recursos naturais para consolidação de sistemas sociais e culturais complexos. Uma vez esgotados tais recursos, essas civilizações entravam em declínio e migravam para novas áreas, onde seria possível, novamente, a exploração de recursos naturais para sua sobrevivência (KHATOUNIAN, 2001).

$\mathrm{Na}$ agricultura atual, devido à escassez de áreas para migração, insumos externos são utilizados em larga escala para evitar a queda da produtividade agrícola. No Brasil, foi a partir da década de setenta que se iniciou esse processo de transformação do setor agrícola, o que ficou conhecido como "Revolução Verde". Sua base era a mecanização agrícola e a utilização de insumos químicos. Essa "revolução", estimulada pelo mercado internacional e apoiada pela política de crédito rural nacional, teve como conseqüências a rápida exaustão dos recursos naturais, a contaminação dos solos, dos cursos de água e dos agricultores, a necessidade de maiores áreas para expansão da fronteira agrícola e o êxodo rural, com o conseqüente inchaço dos centros urbanos, devido à insustentabilidade desse "modelo", visto seu elevado custo de implantação e manutenção.

Assim, tornou-se necessário gerar novas "tecnologias", que fossem capazes de manter e expandir as conquistas da produção minimizando os impactos sobre os recursos naturais e humanos. Surgiu, a partir disso, a tendência agroecológica, que considera os sistemas produtivos como uma unidade sustentável, na qual as transformações orgânicas e energéticas, os processos biológicos e as relações socioeconômicas são estreitas e analisadas como um todo (ALTIERI, 1989).

Nesse contexto, surgem os Sistemas Agroflorestais (SAFs), definidos por Nair (1993) como sistemas e tecnologias de uso da terra, onde lenhosas perenes são utilizadas em um manejo combinado com cultivos agrícolas e/ou animais, com alguma forma de arranjo espacial ou em seqüência temporal.

Os Sistemas Agroflorestais apresentam um enorme potencial como fonte de soluções alternativas para os problemas enfrentados na agricultura convencional, principalmente aos pequenos produtores. Segundo Montagnini et al. (1992), os SAFs adaptam-se muito bem ao esquema de produção da agricultura familiar, por potencializarem o uso da mão-de-obra disponível na propriedade, assim como a diversificação e integração dos policultivos são extremamente benéficos às condições socioculturais dos pequenos produtores. Esses sistemas também constituem uma alternativa para minimizar a degradação ambiental, uma vez que há melhor utilização dos recursos naturais disponíveis (nutrientes, água e luz) e o componente arbóreo geralmente contribui para proteção e melhoria das condições de solo (aumenta a ciclagem de nutrientes e diminui a erosão).

Assim, uma importante característica dos SAFs é que eles estão inseridos numa perspectiva de sustentabilidade em seu escopo ambiental, uma vez que a perenidade implica o uso permanente da mesma área, o que necessita de certa estabilidade do sistema (DANTAS, 1994). Entretanto, para que os Sistemas Agroflorestais possam se projetar como vetores do desenvolvimento sustentável, torna-se essencial o entendimento de seus preceitos básicos, ou seja, suas potencialidades e limitações não apenas sob seus princípios ambientais, mas também econômicos e sociais, uma vez que estes são a base do triângulo da sustentabilidade (MACEDO; CAMARGO, 1994). Mooney (1993) complementa que a sustentabilidade, em sua vertente econômica, depende da integridade ambiental do agroecossistema.

Apesar do exposto, os Sistemas Agroflorestais não são adotados em larga escala no Brasil. Em geral, são praticados pelos pequenos produtores em áreas marginais da propriedade ou em terrenos já degradados (FERNANDES; BONETTI FILHO; SILVA, 1994). Os pequenos fragmentos, presentes nas propriedades agrícolas como áreas de Reserva Legal e de Preservação Permanente, são considerados como "terras improdutivas", um verdadeiro empecilho à maximização do uso da terra (VALLADARESPÁDUA et al., 1997). Também essas comunidades têm dificuldade para compreender os complexos mecanismos e benefícios biológicos decorrentes da prática agroflorestal.

Por isso, as considerações econômicas e sociais, sendo mais facilmente compreendidas, devem ser sempre exaltadas (BERTALOT; MENDONZA; GUERRINI, 2000).

Também a adoção de sistemas agroflorestais em larga escala requer mais do que conhecimentos técnicos. É preciso a adoção de políticas agrícolas adequadas, como manutenção e divulgação dos preços mínimos, linhas de crédito específicas, melhoria dos sistemas de transporte e incentivos para promover o beneficiamento dos produtos agrícolas florestais (DUBOIS et al., 1996).

Diante do exposto, esta pesquisa teve como objetivo a aplicação de indicadores econômicos em um sistema agroflorestal Taungya, implantado para a recuperação de uma área de Reserva Legal no assentamento Santa Zélia, município de Teodoro Sampaio (SP), e com isso contribuir para que, sob a 
ótica da sustentabilidade em seu aspecto econômico, os Sistemas Agroflorestais possam ser divulgados como mecanismo adequado para a recomposição florestal em áreas de Reserva Legal.

\section{METODOLOGIA}

\section{Caracterização da área de estudo}

O Pontal do Paranapanema localiza-se no extremo oeste do estado de São Paulo, entre as confluências dos rios Paraná e Paranapanema. É a segunda região mais pobre do estado, marcada pela recente e voraz devastação florestal, intensificada a partir da década de 1950, que transformou a paisagem da região em extensas áreas de monocultivos e pastagem (VALLADARES-PÁDUA et al., 2002).

A vegetação característica da região é classificada como Floresta Estacional Semidecidual. Existem dois tipos predominantes de solos na região, os latossolos vermelho-escuros e os podzólicos, que interagem com outras formações em menores proporções. Os solos são, na sua maioria, muito arenosos, pouco ácidos, pobres em argila e de grande profundidade (1 a 3 metros), conseqüentemente, de alta drenagem (ATLAS INTERATIVO DO PONTAL DO PARANAPANEMA, 2001). Devido à sua fragilidade natural, manejos apropriados são fundamentais para evitar grandes processos erosivos, o que torna as terras do Pontal aptas apenas às lavouras que requerem pouca mecanização (DITT, 2002).

No que tange aos aspectos climatológicos, a região caracteriza-se, segundo a classificação de Köppen, pelo clima Cwa: mesotérmico, de inverno seco, caracterizado por temperaturas médias anuais ligeiramente inferiores a $22{ }^{\circ} \mathrm{C}$, com chuvas típicas de clima tropical (LEITE, 1998).

O Pontal do Paranapanema é a região mais recentemente devastada no estado de São Paulo. Até 1942 , os quase 247.000 hectares que contemplam a região possuíam cobertura vegetal, o que era conhecido como "Grande Reserva do Pontal". Hoje restam apenas 1,85\% dela, contida no Parque Estadual Morro do Diabo, Estação Ecológica Mico-Leão-Preto e fragmentos adjacentes (SMA/SP, 1999).

Essa devastação aconteceu associada à grilagem de terras, que acabou desencadeando um cenário próprio para a atuação de um dos maiores movimentos sociais do país, o Movimento dos Trabalhadores Rurais Sem Terra (MST), que faz atualmente do Pontal um dos locais mais conhecidos em todo o país por conseqüência dos conflitos pela posse de terra, sendo uma região cuja paisagem é composta por diversos assentamentos rurais.

Entre os inúmeros assentamentos, tem-se o Santa Zélia, localizado no município de Teodoro Sampaio, havendo, atualmente, 104 famílias assentadas. Possui uma área de 2.730 hectares de domínio estadual, demarcada em 1999 (VALENCIANO, 2001), sendo 546 hectares (20\%) alocados como Reservas Legais (conceito disposto no inc. III do parágrafo $2^{\circ}$ do art. $1^{\circ}$ da Lei $\mathrm{n}^{\circ} 4.771$, de 15 de setembro de 1965). Parte desse total necessita ser restaurado, pois se encontra totalmente degradado, conforme disposto no art. 44 da Lei 4.771 de 15 de setembro de 1965.

A área experimental de Reserva Legal implantada nesse assentamento por meio de sistema agroflorestal totaliza 27,5 hectares. Os custos iniciais do sistema (preparo do solo e aquisição das mudas florestais) foram financiados pela organização não-governamental IPE (Instituto de Pesquisas Ecológicas), como parte do programa de Agroflorestas e Corredores Ecológicos da instituição.

O manejo agrícola foi conduzido por 11 famílias moradoras do assentamento, individualmente, resultando em 11 módulos agroflorestais distintos de 2,5 hectares cada um. $\mathrm{O}$ espaçamento entre as espécies arbóreas foi de $3 \mathrm{~m} \times 2 \mathrm{~m}$ em toda a área. A prática agroflorestal adotada foi o chamado Sistema Taungya, definido por Nair (1993) como um consórcio entre árvores e culturas agrícolas por curto período de tempo, sendo que as culturas agrícolas permanecem no sítio até que o sombreamento da copa das árvores permita a produção. Esse tipo de consórcio envolve espécies florestais de interesse econômico, uma vez que elas representariam o componente econômico após um determinado período.

No entanto, na área de Reserva Legal do assentamento Santa Zélia, as árvores não representam um componente econômico, tendo apenas papel ambiental na restauração de um fragmento florestal, e as onze famílias envolvidas no projeto irão cultivar as entrelinhas do sistema enquanto o sombreamento do componente arbóreo permitir.

\section{Critérios de avaliação econômica}

Como indicadores de rentabilidade, e em concordância com diversos autores (CONTADOR, 1997; OLIVEIRA; VOSTI, 1997; DOSSA, 2000; DOSSA et al., 2000; SANTOS; CAMPOS, 2000; SILVA, 2000; 
TSUKAMOTO FILHO, 2003), no presente trabalho foram utilizados o Valor Presente Líquido (VPL), a Relação Benefício Custo (RB/C) e o Retorno de Investimento - Payback. Assim, tem-se:

a) Valor Presente Líquido (VPL): entre as alternativas mais sólidas para análise de investimentos, tem-se como o dado mais consistente o VPL, que estima o valor atual de um fluxo de caixa, usando para isso uma taxa mínima de atratividade do capital. Assim, o VPL determina a viabilidade de um cultivo pela diferença positiva entre benefícios e custos. A atividade será desejável se o VPL for superior ao valor do investimento, pagando-se a taxa de juros usada. Logo, devem-se trazer os valores de cada período de tempo para o valor atual, tanto dos investimentos como dos custos e receitas (DOSSA et al., 2000).

b) Relação Benefício-Custo (RB/C): a Relação $\mathrm{B} / \mathrm{C}$ é um indicador de eficiência econômico-financeira por sugerir o retorno dos investimentos a partir da relação entre a receita total e as despesas efetuadas para viabilizá-los, ou seja, indica quantas unidades de capital recebido como benefícios são obtidos para cada unidade de capital investido (DOSSA et al., 2000).

c) Payback: é considerado o método mais simples e conhecido de avaliação econômica de projetos, servindo para determinar o período de tempo necessário para a recuperação do capital investido em uma determinada atividade, independentemente do uso de uma taxa de juros (CONTADOR, 1997). Como parâmetro de definição, tem-se que quanto menor o payback, melhor o projeto ou a atividade testada (SILVA, 2000).

A coleta dos dados foi realizada por meio de entrevistas mensais com as onze famílias envolvidas no projeto, para o levantamento de todos os custos e benefícios gerados desde o início do plantio. Assim, consideraram-se como custos tudo aquilo que foi gasto pelos produtores para o plantio e manejo da área, o que inclui a mão-de-obra, remunerada ao valor de $\mathrm{R} \$ 18,00 /$ dia, que é o valor pago na região. Os benefícios se referem aos valores de produção e comercialização das culturas agrícolas produzidas na área. Nos casos em que parte da safra foi destinada ao consumo familiar, atribui-se a ela $o$ valor de custo da referida cultura na época em que foi produzida. O período de análise se refere ao primeiro ano de cultivo agrícola da área.

A tabulação dos dados e o cálculo dos critérios de avaliação foram realizados usando-se uma planilha do Microsoft Excel 2000.

\section{RESULTADOS E DISCUSSÃO}

A tabela 1 apresenta os resultados obtidos para o Valor Presente Líquido (VPL) e a Relação Benefício-Custo (RB/C) nos onze módulos agroflorestais analisados durante o primeiro ano de cultivo do sistema. Nessa primeira análise, não estão inclusos os custos iniciais (preparo de solo e aquisição das mudas) com a implantação do sistema, uma vez que eles foram subsidiados às famílias como incentivo para sua implantação.

Tabela 1. Indicadores de avaliação econômica para os onze módulos agroflorestais implantados pelas famílias do assentamento Santa Zélia na área de Reserva Legal.

Table 1. Indicators of economic evaluation for the eleven implanted agroforestry modules by the families of the Santa Zélia settlement in the Legal Reserve.

\begin{tabular}{lcc}
\hline Famílias & VPL & RB/C \\
\hline 1 & $\mathrm{R} \$ 191,81$ & $\mathrm{R} \$ 1,13$ \\
2 & $\mathrm{R} \$ 482,45$ & $\mathrm{R} \$ 2,40$ \\
3 & $\mathrm{R} \$ 303,63$ & $\mathrm{R} \$ 1,58$ \\
4 & $\mathrm{R} \$ 237,27$ & $\mathrm{R} \$ 1,83$ \\
5 & $\mathrm{R} \$ 60,54$ & $\mathrm{R} \$ 1,02$ \\
6 & $\mathrm{R} \$ 641,60$ & $\mathrm{R} \$ 2,79$ \\
7 & $-\mathrm{R} \$ 118,00$ & $\mathrm{R} \$ 0,55$ \\
8 & $-\mathrm{R} \$ 101,00$ & $\mathrm{R} \$ 0,57$ \\
9 & $\mathrm{R} \$ 47,72$ & $\mathrm{R} \$ 1,05$ \\
10 & $\mathrm{R} \$ 50,90$ & $\mathrm{R} \$ 0,96$ \\
11 & $-\mathrm{R} \$ 22,72$ & $\mathrm{R} \$ 0,78$ \\
\hline
\end{tabular}


Pode-se interpretar o VPL como sendo o lucro obtido pela atividade, descontada a taxa de juros de mercado (a taxa de juros utilizada foi de $10 \%$ ao ano). Portanto, valores positivos indicam que a atividade é viável economicamente. A RB/C é o retorno de capital para cada unidade monetária investida. Assim, valores inferiores a $\mathrm{R} \$ 1,00$ indicam prejuízo de investimentos.

Os resultados mostram que três das onze famílias analisadas não tiveram sucesso econômico com a produção agrícola. A justificativa das famílias para a não-rentabilidade foi a baixa produção agrícola devido à estiagem prolongada subseqüente ao plantio e atípica para a época. Mesmo as famílias que tiveram retornos satisfatórios alegam que a produção poderia ter sido maior caso as condições climáticas tivessem sido normais.

Tal observação é importante, uma vez que os resultados apresentados nesta pesquisa incluem todos os benefícios gerados para as famílias com a área de Reserva Legal. Assim, os números incluem as diárias recebidas pelas famílias para o plantio das mudas das espécies arbóreas, o que elevou a rentabilidade do sistema. Sem esses valores, as famílias 5, 9 e 10 também apresentariam valores negativos para os indicadores econômicos utilizados, por apresentarem uma baixa produção agrícola.

A tabela 2 apresenta a produção agrícola de cada módulo agroflorestal na área durante o primeiro ano de cultivo do sistema. Observa-se que as famílias com maior rentabilidade foram as famílias 2 e 6 , sendo que a família 2 foi a que teve maior diversificação de cultivos e a 6 a que teve maior safra.

Tabela 2. Culturas agrícolas produzidas pelas famílias do assentamento Santa Zélia nos módulos agroflorestais na área de reserva legal.

Table 2. Agricultural cultures produced by the families of the Santa Zélia settlement, on the agroforestry modules in legal reserve

\begin{tabular}{lcc}
\hline Famílias & Produção & Quantidade \\
\hline 1 & Milho & 100 balaios \\
& Feijão & $40 \mathrm{~kg}$ \\
2 & Maxixe & $150 \mathrm{~kg}$ \\
& Quiabo & $150 \mathrm{~kg}$ \\
& Abóbora & $200 \mathrm{~kg}$ \\
& Milho & 36 balaios \\
3 & Feijão & $27 \mathrm{~kg}$ \\
4 & Feijão & $340 \mathrm{~kg}$ \\
& Milho & 5 balaios \\
5 & Feijão & $200 \mathrm{~kg}$ \\
6 & Feijão & $100 \mathrm{~kg}$ \\
& Milho & $80 \mathrm{balaios}$ \\
7 & Feijão & $240 \mathrm{~kg}$ \\
8 & Feijão & $100 \mathrm{~kg}$ \\
& Abóbora & $150 \mathrm{~kg}$ \\
9 & Feijão & $80 \mathrm{~kg}$ \\
& Feijão & $15 \mathrm{~kg}$ \\
10 & Milho & 10 balaios \\
& Feijão & $40 \mathrm{~kg}$ \\
11 & Milho & $40 \mathrm{balaios}$ \\
& Feijão & $150 \mathrm{~kg}$ \\
${ }^{1}$ Medida adotada na região, correspondente a 14 kg de milho em espiga. Pesquisa de campo, 2006.
\end{tabular}

Um dos propósitos dos sistemas agroflorestais consiste em diversificar a produção de quem o implanta, possibilitando tanto a melhoria do nível de vida da família - com a elevação do autoconsumo como a diminuição dos riscos dos empreendimentos, mediante geração de renda pelo conjunto das culturas do sistema, bem como pela diminuição da dependência econômica que geralmente sofre um produtor de monocultivo (REYDON et al. 2002).

Diversos autores apontam para o sucesso econômico em projetos envolvendo SAFs (SANTOS, 2000; SILVA, 2000; REYDON et al., 2002; ARCO-VERDE et al., 2003; BENTES-GAMA, et al., 2005) na região Norte do Brasil, que é onde se concentram a maioria das iniciativas agroflorestais em nosso país e onde os SAFs podem contar com o uso de espécies arbóreas típicas da região, que possuem alto valor 
econômico agregado, como é o caso da pupunha (Bractis gasipaes), do açaizeiro (Euterpe oleraceae) e da castanheira (Bertholletia excelsa), dentre outras.

Entretanto, na região do Pontal do Paranapanema, dois estudos já desenvolvidos apontam para a viabilidade econômica do uso de Sistemas Agroflorestais por agricultores assentados (SANTOS; PAIVA, 2002; RODRIGUES et al., 2007). De acordo com Leite et al. (2006), existe um grande potencial para se trabalhar as áreas de Reserva Legal e áreas ocupadas por vegetação secundária em assentamentos de reforma agrária no Pontal utilizando sistemas agroflorestais. Segundo os mesmo autores, além de proporcionar uma diversificação nas fontes de renda e favorecer a segurança alimentar das famílias, a implantação de módulos agroflorestais pode contribuir para a fixação da mão-de-obra no campo e para a organização coletiva das famílias no assentamento, sendo assim um passo importante para contribuir no desenvolvimento endógeno dos assentamentos de reforma agrária.

A função das análises econômico-financeiras é apoiar o processo de tomada de decisão, tanto dos produtores como dos pesquisadores que desenvolvem novos projetos e tecnologias no setor. É através dessas análises que será possível assegurar os recursos destinados à produção e formular recomendações de opções produtivas mais vantajosas de se implementar (CALVO; GÓMEZ, 2000).

Daniel (2000) ainda aponta os rendimentos econômicos como sendo um dos indicadores de sustentabilidade em Sistemas Agroflorestais. O autor afirma que a agregação de valor às culturas produzidas e a sua comercialização são elementos que permitem a "operação" do sistema e seu monitoramento em longo prazo.

Nesse contexto, deve-se ter claro que o benefício econômico é conseqüência de interações biológicas favoráveis entre os diversos componentes do sistema (SILVA, 2000). Assim, torna-se impossível dissociar os diversos elementos que constituem um SAF: sua sustentabilidade socioeconômica vai depender diretamente de sua sustentabilidade ambiental.

No entanto, Ferraz (2003) afirma que, embora teoricamente deva existir um equilíbrio entre as três dimensões da sustentabilidade (social, econômica e ambiental), a abordagem econômica é a mais enfatizada nas avaliações de agroecossistemas, devido ao seu elevado peso nas decisões humanas.

Porém, as interpretações convencionais confundem a sustentabilidade econômica com a perdurabilidade da produção e do máximo do rendimento. Para a avaliação econômica da lucratividade, é necessária uma ou várias safras para análise, havendo, portanto, uma pequena escala de tempo. Já a avaliação da sustentabilidade econômica requer maior escala temporal e não pode estar dissociada de sua escala sistêmica, ou seja, da amplitude da área de estudo, o que leva em consideração suas características hierárquicas e a complementaridade com o ambiente externo (FERRAZ, 2003).

Assim, neste estudo, a análise econômica do consórcio agroflorestal está associada à microeconomia das unidades produtivas da propriedade rural em pequena escala temporal, que, de acordo com Dossa et al. (2000), se caracteriza pela natureza das atividades agrícolas, pelos meios de produção disponíveis e pela qualificação da força de trabalho colocada para produzir mais eficientemente.

Em geral, o que se espera de um sistema de produção é a otimização do uso dos fatores de produção (terra, mão-de-obra, capital e tecnologia) com redução de custos, o que gera, conseqüentemente, maior renda na propriedade. Porém, essa é uma situação específica, na qual o objetivo final da implantação do sistema é o estabelecimento de um fragmento florestal, onde não haverá mais o cultivo nas entrelinhas. Portanto, torna-se impossível fazer considerações sobre a sustentabilidade desse consórcio, visto que essa associação entre as árvores e as culturas agrícolas é temporária e o componente arbóreo não representa um elemento produtivo. Porém, isso não inviabiliza as análises econômicas sobre a geração de renda para essas famílias, nem descarta o uso dos Sistemas Agroflorestais como sistema de produção permanente e sustentável para agricultores assentados no Pontal do Paranapanema.

A tabela 3 apresenta os custos gerais (ou seja, aqueles gerados com a implantação do sistema) e os benefícios totais (referentes à produção agrícola das famílias envolvidas) gerados durante o primeiro ano de cultivo da área de Reserva Legal.

Aplicando-se o payback, o tempo de retorno do investimento, considerando a produção agrícola do primeiro ano na área, seria de 12 anos. É um tempo muito grande para retorno do capital investido em qualquer projeto. Porém, vale ressaltar que a área teve como empecilho uma estiagem prolongada, que prejudicou a produtividade agrícola no seu primeiro ano. Também o SAF implantado não utiliza espécies arbóreas de interesse econômico nem culturas perenes, visto que o manejo agroflorestal na Reserva Legal é temporário. Esses fatores certamente agregariam mais valor ao SAF, tornando o payback viável em 
menor tempo, e abririam espaço para a discussão do uso sustentável da Reserva Legal a médio e longo prazo.

Tabela 3. Custos e benefícios totais gerados com a implantação da área de Reserva Legal do assentamento Santa Zélia.

Table 3. Total costs and benefits generated with the implantation of the area of Legal Reserve of the Santa Zélia settlement.

\begin{tabular}{lccc}
\hline & Atividade & Descrição & Valor (R\$/ha) \\
\hline Custos $^{1}$ & Implantação do povoamento florestal & Preparo do terreno e aquisição & 780,00 \\
& Mão-de-obra & das mudas florestais & 122,13 \\
& Culturas agrícolas & Familiar/externa & 15,86 \\
Benefícios $^{2}$ & Receitas geradas durante o período & Aquisição de sementes & Produção agrícola \\
\hline
\end{tabular}

${ }^{1}$ Instituto de Pesquisas Ecológicas e ${ }^{2}$ Pesquisa de campo, 2006.

Assim, a utilização de Sistemas Agroflorestais na recuperação de áreas degradadas pode constituir uma estratégia interessante, não apenas pelo retorno financeiro imediato, gerado com a produção agrícola, mas também pela manutenção do plantio florestal.

Atualmente, o controle de espécies invasoras em projetos de recuperação ambiental é uma das etapas mais críticas e onerosas de todo o processo. Portanto, técnicas de manejo que visem redução de custos e controlem com eficiência as espécies invasoras são fundamentais para garantir o sucesso dos plantios realizados para a restauração de áreas degradadas (ZILLER, 2000). Rosário et al. (2006) apontam os SAFs como eficientes no controle de espécies invasoras, utilizando plantio adensado das espécies de interesse econômico.

Isso tem fundamental importância, uma vez que, em plantios de restauração, os custos com manutenção do plantio muitas vezes ultrapassam os custos com a sua implantação. Dessa maneira, um processo participativo, como o que foi adotado no Pontal do Paranapanema, poderia reduzir esses custos, não apenas pelas receitas geradas pelo consórcio com culturas agrícolas como também pela economia com manutenção do plantio quando utilizados na recuperação de áreas degradadas, se comparados aos projetos de restauração ecológica que não visam cultivo e utilização da terra.

\section{CONCLUSÕES}

Apesar do subsídio inicial para implantação do Sistema Agroflorestal Taungya, este constitui-se em uma importante ferramenta na recuperação de áreas de Reserva Legal, e seu uso deve ser considerado na restauração dos ecossistemas, uma vez que estes podem cumprir um papel inovador, conciliando restauração, conservação e produção.

A produção agrícola no sistema tem enorme potencial para a geração de renda e bens de consumo. No estudo de caso aqui presente, conclui-se que o insucesso econômico dos SAFs está atrelado às oscilações e instabilidades climáticas durante a produção e não ao sistema propriamente dito.

A remuneração da mão-de-obra para plantio das mudas no sistema pode ser uma estratégia de incentivo aos agricultores para adotarem os SAFs em suas propriedades, e seus custos poderiam ser pensados como parte dos planos de recuperação de áreas de Reserva Legal nas entidades em que se desenvolvem essas ações. No caso específico dessa pesquisa, tais valores foram fundamentais para números positivos dos indicadores utilizados.

Por fim, recomenda-se que novas pesquisas sejam feitas na região, com o propósito de avaliar o desenvolvimento dessas áreas a longo prazo, que permitam avaliar a produtividade da área para cada cultura praticada, fazendo comparações com as médias de produção encontradas na região e analisando o máximo de retorno (produtivo e financeiro) que pode ser esperado por hectare plantado. Também seria fundamental proporcionar maiores vivências em Sistemas Agroflorestais para as famílias que irão se envolver futuramente em projetos dessa natureza, para que elas tenham plena compreensão dessa prática agrícola como oportunidade produtiva e financeira associada à recuperação florestal. 


\section{REFERÊNCIAS}

ALTIERI, M. Agroecologia: as bases científicas da agricultura alternativa. Rio de Janeiro: PTA/FASE, 1989.

ARCO-VERDE, M. F. et al. Avaliação silvicultural, agronômica e socioeconômica de sistemas agroflorestais em áreas desmatadas de ecossistemas de mata e cerrado de Roraima. In: BRASIL. Ministério de Ciência e Tecnologia. Resultados de Projetos de Pesquisa Dirigida (PPDs) - PPG7. Brasília, DF, 2003. p. 95-99.

ATLAS INTERATIVO DO PONTAL DO PARANAPANEMA. Disponível em: $<$ www.multimidia.prudente.unesp.br/atlaspontal>. Acesso em: 29/01/2004.

BENTES-GAMA, M. M. Análise Econômica de Sistemas Agroflorestais na Amazônia Ocidental, Machadinho D’oeste- RO. Revista Árvore, Visçosa, MG, v. 29, n. 3, p. 401-411, 2005.

BERTALOT, M. J.A.; MENDONZA, E.; GUERRINI, I. A. Regeneração da paisagem, estabelecimento e manejo de sistemas agroflorestais. In: ENCONTRO FLORESTAS NATIVAS E SISTEMAS AGROFLORESTAIS: MÉTODOS DE RECUPERAÇÃO E MANEJO, 5., 2000, Botucatu. Anais do ... Botucatu: IBD, 2000.

CALVO, G.; GÓMEZ, M. Economía de sistemas agroforestales: aplicaciónes practicas del análisis económico financeiro em sistemas agroforestales. Costa Rica: Centro Agronómico Tropical de Investigación y Enseñanza, 2000.

CONTADOR, C. R. Projetos sociais, avaliação e prática. 3. ed. São Paulo: Atlas, 1997.

DANIEL, O. et al. Proposta de um conjunto mínimo de indicadores sócio-econômicos para o monitoramento da sustentabilidade em Sistemas Agroflorestais. Revista Árvore, Visçosa, MG, v. 24, n. 3, p. 283-290, 2000.

DANTAS, M. Aspectos Ambientais dos Sistemas Agroflorestais. In: CONGRESSO BRASILEIRO SOBRE SISTEMAS AGROFLORESTAIS, 1., 1994, Porto Velho. Anais... Colombo: EMBRAPA, 1994. v.2. p 433-453.

DITT, E. H. Fragmentos florestais no Pontal do Paranapanema. São Paulo: Annablume/IPÊ/IIEB, 2002.

DOSSA, D. A decisão econômica num sistema agroflorestal. Colombo: Embrapa - Florestas, 2000.

DOSSA, D. et al. Aplicativo com análise de rentabilidade para sistemas de produção de florestas cultivadas e de grãos. Colombo: Embrapa - Florestas, 2000.

DUBOIS, J. et al .Manual agroflorestal para a Amazônia. Rio de Janeiro:REBRAF, 1996.

FERNANDES, E. N.; BONETTI FILHO, R. Z.; SILVA, E. Avaliação de impactos ambientais de Sistemas Agroflorestais. CONGRESSO BRASILEIRO SOBRE SISTEMAS AGROFLORESTAIS, 1., 1994, Porto Velho. Anais... Colombo: EMBRAPA, 1994. v.2. p 361-372.

FERRAZ, J. M. G. As dimensões da sustentabilidade e seus indicadores In: MARQUES, J. F.; SKORUPA, L. A.;FERRAZ, J. M. G. Indicadores de sustentabilidade em agroecossistemas. Jaguariúna: EMBRAPA, 2003, p. 17-35.

KHATOUNIAN, C. A. A reconstrução ecológica da agricultura. Botucatu: Agroecológica, 2001.

LEITE, J. F. A ocupação do Pontal do Paranapanema. São Paulo: Hucitec, 1998.

LEITE, A. Z. Diagnóstico sócio-ambiental de um assentamento com áreas de vegetação secundária no Pontal do Paranapanema: potencialidades para sistemas agroflorestais. In: CONGRESSO BRASILEIRO DE SISTEMAS AGROFLORESTAIS, 6., 2006, Campos dos Goytacazes. Anais... Campos dos Goytacazes: UENF , 2006.

MACEDO, R. L. G.; CAMARGO, I. P. Sistemas Agroflorestais no contexto do desenvolvimento sustentável. In: CONGRESSO BRASILEIRO SOBRE SISTEMAS AGROFLORESTAIS, 1., 1994, Porto Velho. Anais... Colombo: EMBRAPA, 1994. v.1. p 43-49. 
MONTAGNINI, F. Sistemas agroforestales: princípios y aplicaciones em los trópicos. 2. ed. San Jose: Organizacion para Estudos Tropicales, 1992.

MOONEY, P. F. Structure and connectivity as measures of sustainability in agroecosystems. In: MERCZYK, J.S.; JOHNSON, D.B. Sustainable landscapes. Canada: Polyscience, 1993.

NAIR, P. K. Ramachandran. An introduction to agroforestry. Netherlands: Kluwer Academic, 1993.

OLIVEIRA, S. J. M.; VOSTI, S. A. Aspectos econômicos de sistemas agroflorestais em Ouro Preto do Oeste, Rondônia. Porto Velho: EMBRAPA/CPAF, 1997.

REYDON, B. P. et. al. Avaliação Econômica de Sistema Agroflorestal para Recuperação de Áreas Degradadas. CONGRESSO BRASILEIRO DE ECONOMIA E SOCIOLOGIA RURAL, 40., 2002, Passo Fundo. Anais do... Passo Fundo: Universidade de Passo Fundo. Disponível em: $<$ http://www.eco.unicamp.br/nea/gestao_ambiental/artigos/ReydonMacielSaldanhaeBatista_AvaliacaoAr boreto.pdf $>$. Acesso em: 18/01/2005.

RODRIGUES, E. R. et.al. Avaliação econômica de sistemas agroflorestais implantados pra a recuperação de reserva legal no Pontal do Paranapanema. Revista Árvore, Viçosa, MG, v. 1, n. 5, 2007.

ROSÁRIO, A. A. S. et.al. Avaliação técnica do plantio adensado em sistemas agroflorestais com relação ao controle de plantas invasoras. 2006.2 Disponível em: $<$ http://www.agrofloresta.net/artigos/plantio_adensado_saf_peneireiro.pdf>. Acesso em: 18/01/2005.

SANTOS, M. J. C. Avaliação econômica de quatro modelos agroflorestais em áreas degradadas por pastagens na Amazônia Ocidental. Dissertação (Mestrado em Ciências Florestais) - Escola Superior de Agricultura “Luiz de Queiroz”, Piracicaba, 2000.

SANTOS, J. C.; CAMPOS, R. T. Metodologia para análise de rentabilidade e riscos de sistemas agroflorestais. Rio Branco: Embrapa Acre, 2000.

SANTOS, M. C.; PAIVA, S. N. Os Sistemas agroflorestais como alternativa econômica em pequenas propriedades rurais: estudo de caso. Revista Ciência Florestal, Santa Maria, v. 1, n. 12, p. 135-141, 2002.

SILVA, I. C. Viabilidade agroeconômica do cultivo do cacaueiro (Theobroma cacao L.) com açaizeiro (Euterpe oleracea Mart.) e com pupunheira (Bractris gasipaes Kunth) em sistemas agroflorestais na Amazônia. 143 f. Tese (Doutorado em Engenharia Florestal) - Setor de Ciências Agrárias, Universidade Federal do Paraná, Curitiba, 2000.

SÃO PAUlO (Estado). Secretaria de Meio Ambiente (SMA-SP). Pontal do Paranapanema: zoneamento ecológico-econômico. São Paulo, 1999.

TSUKAMOTO FILHO, A. A. Análise econômica de um plantio de Teca submetido a desbastes. Revista Árvore, Viçosa, MG, v.27, n. 4, 2003. Disponível em: $<$ http://www.scielo.br/scielo.php?script=sci_arttext\&pid=S0100$67622003000400009 \& \operatorname{lng}=\mathrm{pt} \& \mathrm{nrm}=\mathrm{iso} \& \mathrm{t} \operatorname{lng}=\mathrm{pt}>$. Acesso em: 18/01/2005.

VALENCIANO, R. C. Processo de luta pela terra e seus desdobramentos no município de Teodoro Sampaio. Revista Pegada Eletrônica, São Paulo, v.2, n.1, 2001. Disponível em: <www2.prudente.unesp.Br/ceget/pegada/peg9n2.htm>. Acesso em: 18/01/2005.

VALLADARES-PADUA, C. et al Resgatando a grande reserva do Pontal do Paranapanema: Reforma Agrária e Conservação de Biodiversidade. In: CONGRESSO BRASILEIRO DE UNIDADES DE CONSERVAÇÃO. 2005, Curitiba. Anais... Curitiba: UNILIVRE/REDEPROUC/IAP, 1997. p.783-792.

VALLADARES-PÁDUA, C. et al. Módulos agroflorestais na conservação de fragmentos florestais da Mata Atlântica. Revista Experiências PDA, Brasília, DF, n. 2, p. 7-33, jan., 2002.

ZILLER, S. R. A estepe gramíneo-lenhosa no segundo planalto do Paraná: diagnóstico ambiental com enfoque à contaminação biológica. $268 \mathrm{f}$. Tese (Doutorado em Engenharia Florestal) - Setor de Ciências Agrárias, Universidade Federal do Paraná, Curitiba, 2000. 